\title{
Localization and Enhanced Current Density of the Kv4.2 Potassium Channel by Interaction with the Actin-Binding Protein Filamin
}

\author{
Kevin Petrecca, David M. Miller, and Alvin Shrier \\ Department of Physiology, McGill University, Montréal, Québec, Canada H3G 1 Y6
}

\begin{abstract}
Kv4.2 potassium channels play a critical role in postsynaptic excitability. Immunocytochemical studies reveal a somatodendritic Kv4.2 expression pattern, with the channels concentrated mainly at dendritic spines. The molecular mechanism that underlies the localization of Kv4.2 to this subcellular region is unknown. We used the yeast two-hybrid system to identify the Kv4.2associated proteins that are involved in channel localization. Here we demonstrate a direct interaction between Kv4.2 and the actin-binding protein, filamin. We show that Kv4.2 and filamin can be coimmunoprecipitated both in vitro and in brain and that Kv4.2 and filamin share an overlapping expression pattern in the cerebellum and cultured hippocampal neurons. To examine the functional consequences of this interaction, we expressed Kv4.2
\end{abstract}

in filamin ${ }^{+}$and filamin ${ }^{-}$cells and performed immunocytochemical and electrophysiological analyses. Our results indicate that Kv4.2 colocalizes with filamin at filopodial roots in filamin ${ }^{+}$cells but shows a nonspecific expression pattern in filamin ${ }^{-}$cells, with no localization to filopodial roots. Furthermore, the magnitude of whole-cell Kv4.2 current density is $\sim 2.7$-fold larger in filamin ${ }^{+}$ cells as compared with these currents in filamin ${ }^{-}$cells. We propose that filamin may function as a scaffold protein in the postsynaptic density, mediating a direct link between Kv4.2 and the actin cytoskeleton, and that this interaction is essential for the generation of appropriate Kv4.2 current densities.

Key words: Kv4.2; potassium channels; filamin; postsynaptic density; subcellular localization; actin-binding protein
Appropriate synaptic transmission is dependent on the precise localization of ion channels and neurotransmitter receptors at specific subcellular sites (Sheng, 1996; Ziff, 1997; Colledge and Froehner, 1998; Craven and Bredt, 1998). Voltage-gated $\mathrm{K}^{+}$channels are expressed within neurons in a variety of spatial distributions (Sheng et al., 1992; Wang et al., 1994; Veh et al., 1995) where they function as regulators of membrane excitability and synaptic transmission (Hille, 1991; Magee et al., 1998). Fast transient (Atype) $\mathrm{K}^{+}$channels, members of the voltage-gated $\mathrm{K}^{+}$channel family that are found in a wide variety of excitable cells, have been implicated in the control of action potential frequency and threshold, action potential configuration, neurotransmitter release, and postsynaptic excitability (Jan and Jan, 1997; Magee et al., 1998). $\mathrm{Kv} 1.4$ and $\mathrm{Kv} 4.2$, fast transient $\mathrm{K}^{+}$channel family members, are segregated differentially in neurons. Kv1.4 is localized to axons exhibiting a concentration at the presynaptic terminal (Sheng et al., 1992; Zito et al., 1997; Arnold and Clapham, 1999), whereas Kv4.2 is localized to the somatodendritic compartment exhibiting a concentration at the postsynaptic terminal (Sheng et al., 1992; MaleticSavatic et al., 1995; Alonso and Widmer, 1997).

In this study we set out to identify Kv4.2-associated proteins that are involved in Kv4.2 localization. Here we report the identification and characterization of a novel interaction between Kv4.2 and filamin, a member of the $\alpha$-actinin/spectrin/dystrophin family of actin-binding proteins. Filamin originally was identified as a protein isolated from motile alveolar macrophage that caused purified muscle actin to gel and precipitate (Hartwig and Stossel, 1975). It is a widely distributed member of a family of actin-binding proteins capable of cross-linking actin filaments into orthogonal arrays and

\footnotetext{
Received July 13, 2000; revised Aug. 28, 2000; accepted Sept. 15, 2000.
}

This work was supported by the Medical Research Council of Canada (A.S.). K.P. was supported by a grant from the Fonds pour la Formation de Chercheurs et l'Aide à la Recherche. We thank Damian G. Wheeler for preparing the cultured hippocampal neurons; Dr. P. A. Janmey (University of Pennsylvania, Philadelphia, PA) for supplying the M2 and A7 cell lines; and Dr. J. M. Nerbonne (Washington University, St. Louis, MO) for providing us with Kv4.2, Kv4.3, and HERG cDNAs and the Kv4.2 and HERG antibodies. We are also grateful to Dr. A. P. Haghighi for a critical reading of this manuscript.

Correspondence should be addressed to Dr. Alvin Shrier, Department of Physiology, McGill University, 3655 Drummond Street, Montréal, Québec, Canada H3G 1Y6. E-mail: ashrier@med.mcgill.ca.

Copyright (C) 2000 Society for Neuroscience $0270-6474 / 00 / 208736-09 \$ 15.00 / 0$ contributes substantially to the formation and structure of the actin meshwork situated immediately subjacent to the surface membrane (Marti et al., 1997).

Here we show that Kv4.2 and filamin can be coimmunoprecipitated from both heterologous cells and brain extracts. Mapping studies reveal that a four amino acid (aa) motif located $\sim 30$ aa upstream of the Kv4.2 C terminus is required for Kv4.2-filamin interaction. We also show that Kv4.2 and filamin share an overlapping expression pattern in the cerebellum and cultured hippocampal neurons. Importantly, we demonstrate that not only does filamin colocalize with Kv4.2 at filopodial roots in heterologous cells, but it mediates Kv4.2 localization at these sites. Moreover, this interaction results in 2.7-fold increase in the magnitude of wholecell Kv4.2 current density. These findings demonstrate that filamin is a Kv4.2-interacting protein that colocalizes with Kv4.2 in neurons and plays an important role in the localization and functional surface membrane expression of Kv4.2 in heterologous cells. We propose that filamin may function as a scaffold protein in the postsynaptic density (PSD), mediating a direct link between Kv4.2 and the actin cytoskeleton, and that this interaction is essential for the generation of appropriate Kv4.2 current densities.

\section{MATERIALS AND METHODS}

Yeast two-hybrid screen and analysis of Kv4.2-filamin interaction. Yeast two-hybrid screens were performed with the Y190 yeast strain harboring the reporter genes HIS3 and $\beta$-galactosidase $(\beta$-gal) under the control of upstream gal4-binding sites (Clontech Laboratories, Palo Alto, CA). The $\mathrm{Kv} 4.2 \mathrm{C} 1$ bait was generated by incorporating unique NcoI and $\mathrm{XbaI}$ restriction sites $5^{\prime}$ and $3^{\prime}$, respectively, via PCR and was fused to the gal4 DNA-binding domain in vector pAS2-1. This bait, pAS2-1/Kv4.2C1, was used to screen $\sim 3 \times 10^{6}$ clones from a human heart cDNA library constructed in the GAL4-activation domain vector pACT-2 (Clontech). Deletion variants of pAS2-1/Kv4.2C1 were constructed by PCR with the use of specific primers and were subcloned into pAS2-1 for yeast twohybrid interactions. Mutations of pAS2-1/ Kv $4.2 \mathrm{C} 1$ were generated by using QuikChange (Stratagene, La Jolla, CA). The Kv4.3C bait was generated in a manner similar to $\mathrm{Kv} 4.2 \mathrm{C} 1$. The HERGC bait was generated by incorporating unique $\mathrm{Nco}$ I and $\mathrm{Bam} \mathrm{HI}$ restriction sites $5^{\prime}$ and $3^{\prime}$, respectively, via PCR and was fused to the gal4 DNA-binding domain in vector pAS2-1. Expression constructs. The GST-Kv4.2(aa 471-630) fusion construct was generated by digesting pAS2-1/Kv4.2C1 with Bam HI and SmaI (aa 471630) and subcloning it into pGEX-2T (Pharmacia, Piscataway, NJ). $\mathrm{pCMV} / \mathrm{myc}-\mathrm{Kv} 4.2$ was generated by subcloning full-length Kv4.2 into pCMV-myc (Stratagene). pSG-5/HA-filamin (filaminC, aa 2172-2705) was generated by subcloning the original pACT-2 library clone, containing 
a 5' HA epitope, into pSG-5 (Stratagene). pCMV/myc-Kv4.2/600 was constructed via PCR with the use of specific primers and was subcloned into $\mathrm{pCMV}$-myc. pCMV/myc-Kv4.2/ATAA mutations were generated with QuikChange (Stratagene). pCMV/myc-HERG was generated by subcloning full-length HERG (generously provided by Dr. J. M. Nerbonne, Washington University, St. Louis, MO) into pCMV-myc (Stratagene).

Transfection and immunocytochemistry in heterologous cells. COS7, M2, and A7 cells were transfected with Lipofectamine (Life Technologies, Gaithersburg, MD) on poly-D-lysine-coated coverslips (for immunocytochemistry) or in $100 \mathrm{~mm}$ tissue culture dishes (for immunoprecipitation experiments). Cells were fixed, permeabilized, and immunolabeled $42 \mathrm{hr}$ after transfection, as described (Petrecca et al., 1999). Rabbit anti-HA (Babco, Richmond, CA) was diluted 1:500; mouse anti-myc (Santa Cruz Biotechnology, Santa Cruz, CA) was used at a concentration of $2 \mu \mathrm{g} / \mathrm{ml}$, and goat anti-filamin (Sigma, St. Louis, MO) was diluted 1:40. Oregon green-conjugated goat anti-rabbit (Molecular Probes, Eugene, OR), Cy3conjugated goat anti-mouse (Jackson ImmunoResearch, West Grove, PA), and FITC-conjugated donkey anti-goat secondary antibodies were used at a dilution of 1:100. Immunofluorescence was visualized with a Bio-Rad MicroRadiance confocal microscope (Hercules, CA) at an optical thickness of $\sim 7 \mu \mathrm{m}$. Digital images were prepared with Adobe Photoshop (Mountainview, CA).

Coimmunoprecipitations. For immunoprecipitation, COS7, filamin ${ }^{+}$, and filamin ${ }^{-}$cells that were plated on $100 \mathrm{~mm}$ dishes were washed in ice-cold PBS, followed by solubilization in $1 \mathrm{ml}$ of ice-cold extraction buffer [(in mM) 50 Tris, pH $7.4,150 \mathrm{NaCl}, 1$ EDTA plus $1 \%$ Nonidet P-40, $0.5 \%$ deoxycholate, and $0.1 \%$ SDS supplemented with $1 \mathrm{~mm}$ phenylmethylsulfonyl fluoride (PMSF) and $10 \mu \mathrm{g} / \mathrm{ml}$ each of pepstatin, aprotinin, and leupeptin]. The extraction was allowed to proceed with shaking for $3 \mathrm{hr}$ a $4^{\circ} \mathrm{C}$. Insoluble material was pelleted by centrifugation at $60,000 \times g$ for 30 min, and the supernatants were used for coimmunoprecipitation. Rabbit anti-HA (1:200) or rabbit anti-Kv4.2 (1:50) antibodies were added to the $100 \mu \mathrm{l}$ of detergent extract, which was incubated with inversion for $2 \mathrm{hr}$ at $4^{\circ} \mathrm{C}$. Equilibrated protein A-Sepharose beads (Pharmacia) were added for a further $2 \mathrm{hr}$ with inversion and then were pelleted by centrifugation. Eluted proteins were resolved by SDS-PAGE, transferred to a polyvinylidene difluoride (PVDF) membrane, and visualized by immunoblotting with mouse anti-myc $(1 \mu \mathrm{g} / \mathrm{ml})$, mouse anti-HA (1:500), or mouse antifilamin (1:500) antibodies, followed by horseradish peroxidase-conjugated goat anti-mouse antibody (1:5000; Jackson ImmunoResearch). Enhanced chemiluminescence was performed by using the $\mathrm{ECL}^{+}$detection kit (Amersham, Arlington Heights, IL). Cerebellar membrane preparations and solubilization were performed according to Luo et al. (1997). Briefly, adult rat cerebellum from Sprague Dawley rats was homogenized in ice-cold 10 $\mathrm{mm}$ Tris- $\mathrm{HCl}, \mathrm{pH} 7.4$, containing $320 \mathrm{~mm}$ sucrose, $1 \mathrm{~mm}$ PMSF, and 10 $\mu \mathrm{g} / \mathrm{ml}$ each of pepstatin, aprotinin, and leupeptin. The tissue homogenate was centrifuged at $700 \times g$ for $10 \mathrm{~min}$ at $4^{\circ} \mathrm{C}$. The pellet was rehomogenized and centrifuged at $700 \times g$; the supernatants were combined and centrifuged at $37,000 \times g$ for $40 \mathrm{~min}$ at $4^{\circ} \mathrm{C}$. This pellet $(\mathrm{P} 2)$ was resuspended in $10 \mathrm{~mm}$ Tris- $\mathrm{HCl}, \mathrm{pH} 7.4$, supplemented with protease inhibitors. Protein concentrations were determined via the Bradford assay. Then the protein $(400 \mu \mathrm{g})$ was solubilized by the addition of $0.1 \mathrm{vol}$ of $10 \%$ sodium deoxycholate in $500 \mathrm{~mm}$ Tris- $\mathrm{HCl}, \mathrm{pH} \mathrm{9.0,} \mathrm{and} \mathrm{incubated} \mathrm{for} 30 \mathrm{~min}$ at $36^{\circ} \mathrm{C}$. A 0.10 vol of $1 \%$ Triton $\mathrm{X}-100 / 50 \mathrm{~mm}$ Tris- $\mathrm{HCl}, \mathrm{pH} 9.0$, was added, and the preparation was dialyzed overnight at $4^{\circ} \mathrm{C}$, followed by centrifugation for $10 \mathrm{~min}$ at $100,000 \times \mathrm{g}$. The supernatant was used for coimmunoprecipitation. Anti-filamin antibodies (1:50, Sigma; 1:20, Serotec, Oxford, UK) were added to the clarified supernatant of the solubilized P2 fraction and were mixed by inversion for $2 \mathrm{hr}$ at $4^{\circ} \mathrm{C}$. Equilibrated protein A-Sepharose beads were added and mixed by inversion for a further $2 \mathrm{hr}$ at $4^{\circ} \mathrm{C}$. Eluted proteins were resolved by SDS-PAGE, transferred to a PVDF membrane, and visualized by immunoblotting with an anti-Kv4.2 antibody generated against Kv4.2 residues 29-38: APPRQERKRT (1:400 Barry et al., 1995) or an anti-HERG antibody generated against HERG residues 1145-1159: LTSQPLHRHGSDPGS (1:500; Pond et al., 2000) followed by horseradish peroxidase-conjugated secondary antibody (1: 5000; Jackson ImmunoResearch). Enhanced chemiluminescence was performed with the $\mathrm{ECL}^{+}$detection kit (Amersham). For antibody controls the immunoprecipitations were performed by using control $\mathrm{IgG}$, and the Kv4.2 antibody was blocked by preincubating with the immunogenic peptide $(100 \mu \mathrm{g} / \mathrm{ml})$.

Filter overlay assays. GST and GST-Kv4.2 (aa 471-630) fusion proteins, prepared from bacterial lysates, were purified with glutathione-Sepharose beads (Pharmacia). GST and GST-Kv4.2 were released from the beads, and $\sim 3 \mu \mathrm{g}$ of each fusion protein was electrophoresed. The resolved proteins were transferred to a PVDF membrane, and the denatured filter-bound proteins were renatured according to Wyszynski and Sheng (1999). Briefly, membranes were incubated in buffer A [(in mM) 10 HEPES, $60 \mathrm{KCl}, 1 \mathrm{EDTA}$, and 1 2-mercaptoethanol] containing $6 \mathrm{~m}$ guanidine hydrochloride for $10 \mathrm{~min}$ at $4^{\circ} \mathrm{C}$. Incubations were repeated for $10 \mathrm{~min}$ at $4^{\circ} \mathrm{C}$, using decreasing concentrations of guanidine hydrochloride $(3,1.5,0.75,0.38,0.19,0.1$, and $0 \mathrm{M})$. pSG-5/filamin $\mathrm{C}$ (aa 2172-2705) was in vitro-translated (Promega, Madison, WI) in the presence of $\left[{ }^{35} \mathrm{~S}\right]$ and used for the binding assay. The membrane was incubated with $10 \mu \mathrm{l}$ of $\left[{ }^{35}\right.$ S]filamin overnight at $4{ }^{\circ} \mathrm{C}$. The next day the membrane was brought to room temperature, washed, and submitted to autoradiography.
Myc-Kv4.2, myc-Kv4.2/600, and myc-Kv4.2/ATAA were in vitrotranslated in the presence of $\left[{ }^{35} \mathrm{~S}\right]$, electrophoresed, transferred, and renatured as above. pSG-5/HA-filamin C (aa 2172-2705) was in vitrotranslated in the absence of $\left[{ }^{35} \mathrm{~S}\right]$ and used for the binding assay as above. The next day the membrane was brought to room temperature, washed, immunoblotted with anti-HA; enhanced chemiluminescence was performed with the $\mathrm{ECL}^{+}$detection kit (Amersham). Then the membrane was stripped and submitted to autoradiography.

Neuron culture and immunocytochemistry. Low-density hippocampal neuronal cultures were prepared from hippocampi dissected from 3-d-old Sprague Dawley rats and stored in an oxygenated solution. Then the hippocampi were exposed to an oxygenated papain solution for $\sim 1 \mathrm{hr}$, dissociated, spun through BSA, resuspended in growth medium [Neurobasal medium supplemented with B-27 (Life Technologies)], and plated on modified $35 \mathrm{~mm}$ culture dishes coated with poly-D-lysine and laminin. After $15 \mathrm{~d}$ in culture the neurons were fixed in methanol for $15 \mathrm{~min}$ at $-20^{\circ} \mathrm{C}$, blocked in $0.5 \%$ BSA for $30 \mathrm{~min}$ at room temperature, and immunolabeled as described above with rabbit and Kv4.2 (1:100) and mouse and filamin (1:100). Synaptophysin SV P38 monoclonal (Sigma) was used at a dilution of 1:500. Immunofluorescence was visualized with a Bio-Rad MicroRadiance confocal microscope at an optical thickness of $\sim 7$ $\mu \mathrm{m}$.

Fresh-frozen adult rat cerebellum was cryosectioned at a thickness of 20 $\mu \mathrm{m}$ and thaw-mounted on Probe-On Plus slides (Fisher Scientific, Pittsburgh, PA). Sections were air-dried at room temperature for $1 \mathrm{hr}$, permeabilized, and blocked in $0.2 \%$ Triton X-100/0.5\% BSA in PBS for $30 \mathrm{~min}$. Sections were incubated with primary antibodies for $1 \mathrm{hr}$ and rinsed in PBS, followed by incubation with secondary antibodies for $1 \mathrm{hr}$. Antibodies were used at the following dilutions: Kv4.2, 1:100; filamin (Sigma), 1:200; synaptophysin, 1:500. Immunofluorescence was visualized with a Bio-Rad MicroRadiance confocal microscope at an optical thickness of $\sim 4 \mu \mathrm{m}$. Digital images were prepared with Adobe Photoshop.

Electrophysiological analysis. Patch-clamp technique, performed with an Axopatch-1D amplifier (Axon Instruments, Foster City, CA), was used to measure whole-cell currents. Patch-clamp electrodes were filled with medium containing (in mM): $130 \mathrm{KCl}, 1 \mathrm{MgCl}_{2}, 5$ EGTA, $5 \mathrm{Mg}$-ATP, and 10 HEPES, pH 7.2. The pipette resistances were 3-4 M $\Omega$. The external medium contained (in $\mathrm{mM}$ ): $137 \mathrm{NaCl}, 4 \mathrm{KCl}, 1.8 \mathrm{CaCl}_{2}, 1 \mathrm{MgCl}_{2}, 10$ glucose, and 10 HEPES, $\mathrm{pH}$ 7.4. Voltage-clamp pulses were delivered with custom-designed software (Alembic Software, Montréal, Québec) implemented on a personal computer equipped with an analog-to-digital board (Omega, Stanford, CT). Data were sampled at $10 \mathrm{kHz}$ and filtered at $2 \mathrm{kHz}$ for storage on computer hard disk and were analyzed with the same software. Raw data are shown without leak correction. All experiments were performed at room temperature $\left(20-22^{\circ} \mathrm{C}\right)$. Activation of Kv4.2 current was induced from a holding potential of $-80 \mathrm{mV}$ by $500 \mathrm{msec}$ depolarizing pulses to potentials between -70 and $70 \mathrm{mV}$ in $10 \mathrm{mV}$ steps that were imposed at intervals of $10 \mathrm{sec}$. In some experiments the holding potential was shifted to $-20 \mathrm{mV}$ to inactivate Kv4.2 channels, and the depolarizing protocol was repeated with steps ranging from -10 to $70 \mathrm{mV}$. Cell capacitance was estimated by fitting the current induced by a small (10 $\mathrm{mV}$ ) hyperpolarizing step and was verified by analog measurement with the patch-clamp amplifier.

\section{RESULTS}

\section{Interaction of Kv4.2 with filamin}

In an effort to search for molecules that may be involved in the localization of Kv4.2, we used the entire $\mathrm{C}$ terminus of Kv4.2 as bait to screen a human heart cDNA library, using the yeast two-hybrid system. The screen yielded multiple copies of four distinct cDNAs encoding polypeptides that interacted specifically with the $\mathrm{C}$ terminus of Kv4.2. No other clones were isolated in this screen. Furthermore, an unrelated bait encoding the $\mathrm{C}$ terminus of HERG did not interact with any of the isolated clones. Sequence analysis revealed that one of the cDNAs was derived from filamin A, whereas the other three cDNAs were derived from distinct but overlapping sequences of a highly homologous polypeptide, filamin C (Fig. $1 A$ ).

Three filamin isoforms (A, B, and C) have been identified, exhibiting an overall amino acid homology of 70-72\%. Each isoform shares three common functional domains: a N-terminal actinbinding domain that is structurally similar to that of the $\alpha$-actinin/ spectrin/dystrophin family of cytoskeletal proteins, a semiflexible rod domain composed of 24 repeats interrupted by two short sequence inserts of 20-40 aa between repeats 15-16 and 23-24, and a C-terminal self-association domain (Xie et al., 1998). All partial filamin cDNA fragments that were isolated in this screen began at variable starting points within repeat 20 and were complete to the $\mathrm{C}$ terminus (Fig. $1 A$ ).

To define the site of interaction between Kv4.2 and filamin, we 
A

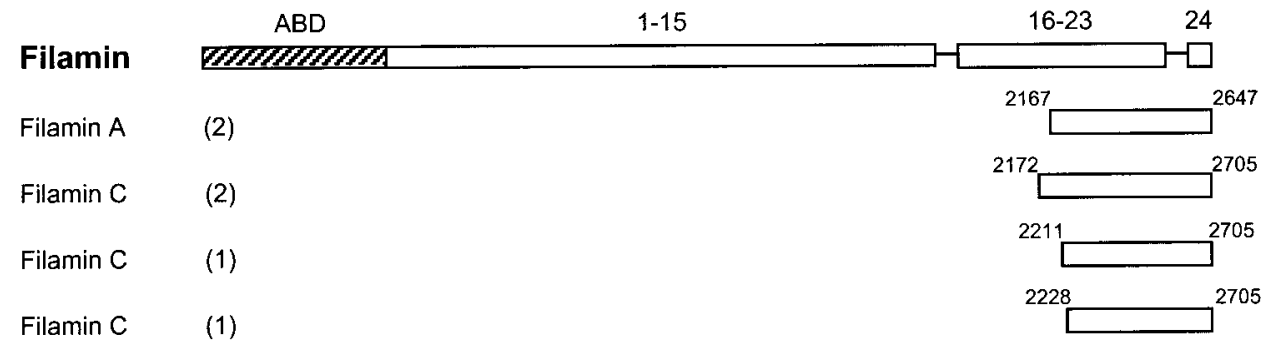

B

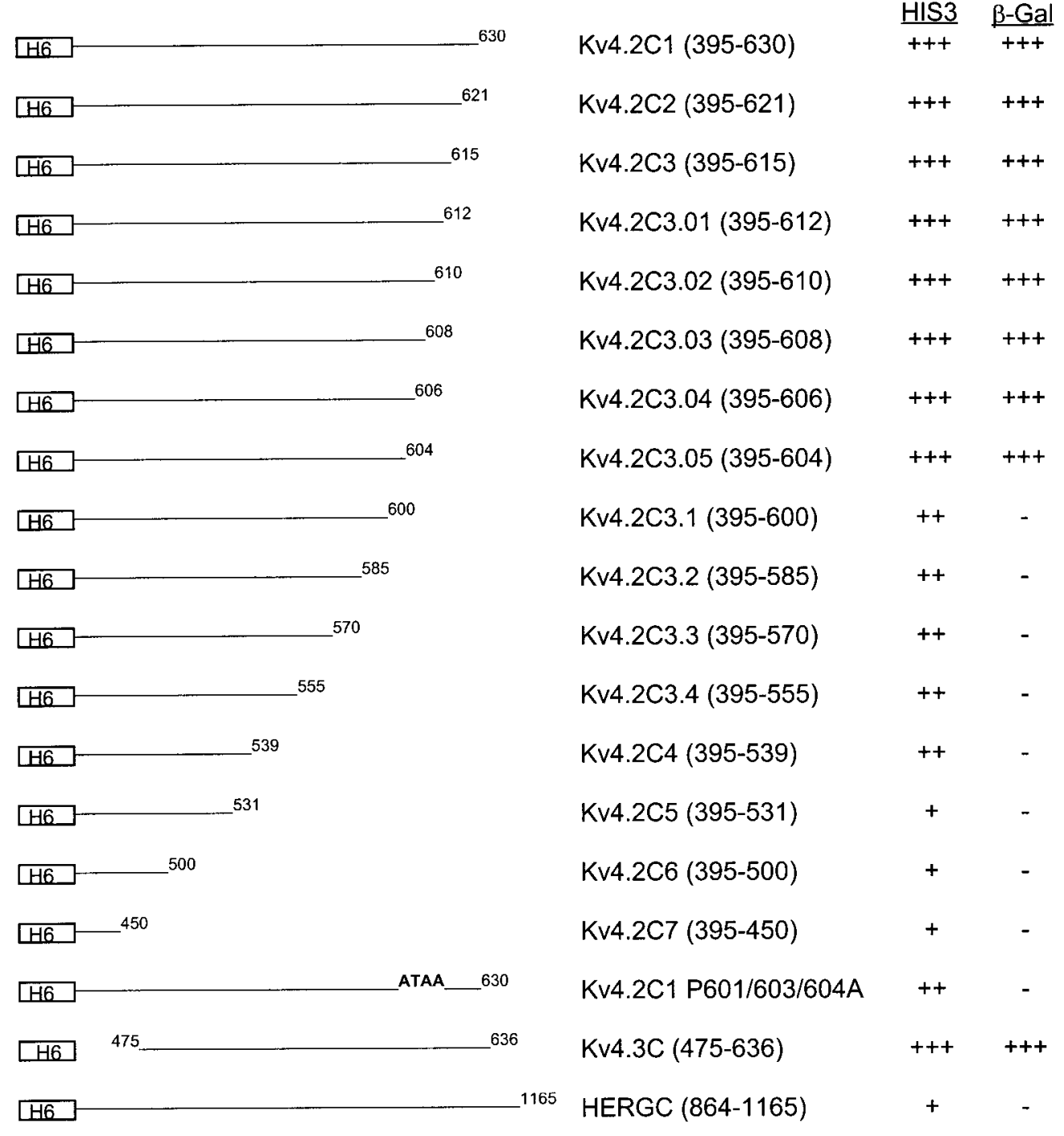

Figure 1. The domain structure of filamin and interaction with Kv4.2. A, Human cDNA clones isolated with a yeast two-hybrid screen, using the Kv4.2 C-terminal region (aa 395-630) as bait, are shown aligned below a schematic representation of the filamin domain structure. $A B D$, Actin binding domain; $1-15,16-23$, and 24 represent $\sim 96$ aa repeats, each separated by hinge regions. Partial cDNAs from filaminA and filaminC genes were isolated. The numbers in parentheses indicate the number of times each clone was isolated with the yeast two-hybrid screen. $B$, Sequence requirements in the Kv4.2 C-terminal region for interaction with filamin. FilaminC (aa 2172-2705), binding to Kv4.2C1 (aa 395-630), and deletion derivatives were assayed by $H I S 3 / \beta$-gal induction in the yeast two-hybrid system. Residues 601-604 are required for interaction with filamin; deletion and/or mutation of this region abolishes the interaction. Kv4.3, which contains the identical binding region, also interacts with filamin. The HERG C-terminal region (aa 864-1165) does bind filamin. The various bait fragments were tested for filamin binding by semiquantitative yeast two-hybrid interaction assays that were based on the degree of induction by the reporter genes HIS3 and $\beta$-gal. HIS3 activity was measured by the percentage of colonies growing on histidine-lacking medium as compared with the full-length Kv4.2 bait $(\mathrm{Kv} 4.2 \mathrm{Cl}):+++,>75 \% ;++,>50 \% ;+,>25 \%$. $\beta$-Gal activity was determined from the time that was taken for the colonies to turn blue in X-gal filter lift assays performed at room temperature:,$+++<2 \mathrm{hr} ;++,<3 \mathrm{hr} ;+,<4 \mathrm{hr} ;-$, no significant activity. $H 6$, Sixth transmembrane domain. 
began by examining successively larger C-terminal deletions of Kv4.2 that bind filamin, using yeast two-hybrid analysis. Deletion of the C-terminal 25 aa did not affect binding (Fig. $1 B$ ). However, deletion of the next four amino acids (601-604) completely abolished the interaction, suggesting that these amino acids (PTPP) are necessary for Kv4.2 interaction with filamin. We next generated point mutations within this region, using the entire $\mathrm{C}$-terminal $\mathrm{Kv} 4.2$ bait fragment (Kv4.2C1). Substitution of the prolines in the 601-604 aa region to alanines (PTPP $\rightarrow$ ATAA) completely abolished the interaction (Fig. $1 B$ ). These observations indicate that this proline-rich region is a domain that is necessary for Kv4.2 interaction with filamin. This sequence was noted to be identical in Kv4.3, consistent with its representing a site of interaction with both members of the Kv4 family. The subsequent use of yeast two-hybrid analysis confirmed that filamin also interacts with Kv4.3 (Fig. 1B).

\section{Association of Kv4.2 and filamin in situ and in vitro}

To investigate the interaction of Kv4.2 and filamin further, we tested whether these proteins form a complex in transfected heterologous cells. COS7 cells, transfected either singly or doubly with HA epitope-tagged filamin (HA-filamin) and myc-tagged Kv4.2 (myc-Kv4.2), myc-Kv4.2/600, or myc-Kv4.2/ATAA, were solubilized and immunoprecipitated with an anti-HA antibody. The

A
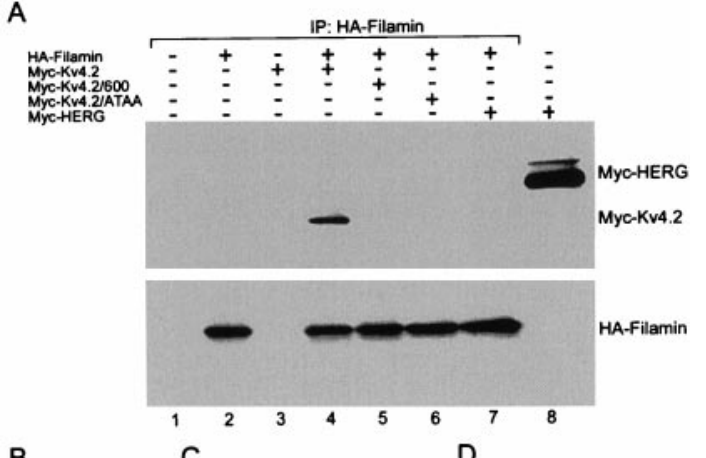

B

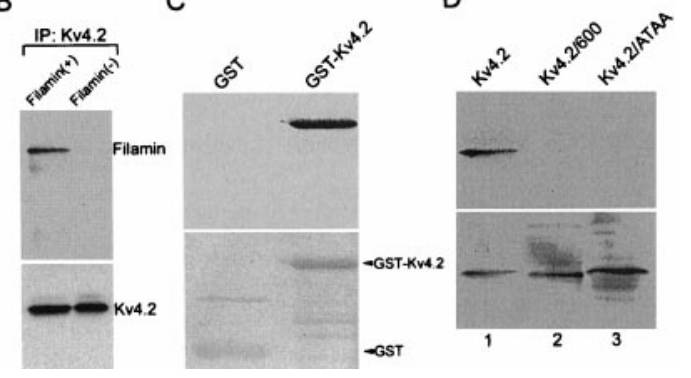

Figure 2. Coimmunoprecipitation in heterologous cells and direct binding of Kv4.2 and filamin. A, Extracts from COS7 cells singly or doubly transfected with HA-filamin and myc Kv4.2, myc-Kv4.2/600, myc-Kv4.2/ATAA, or myc-HERG were immunoprecipitated with anti-HA antibodies. The immunoprecipitates were immunoblotted with anti-myc (top panel) and anti-HA antibodies (bottom panel). B, Extracts from Kv4.2-transfected filamin $^{+}$and filamin ${ }^{-}$cells were immunoprecipitated with anti-Kv4.2 antibodies and immunoblotted with anti-filamin (top panel) and anti-Kv4.2 (bottom panel) antibodies. $C$, Filter overlay assay showing direct in vitro binding of $\left[{ }^{35} \mathrm{~S}\right]$ filamin to Kv4.2. Glutathione $S$-transferase $(G S T)$ and GST-Kv4.2 (aa 417-630) fusion proteins were prepared as crude bacterial lysates and were purified with glutathione-Sepharose beads. Protein $(5 \mu \mathrm{g})$ was resolved by SDS-PAGE and transferred to a PVDF membrane. Top panel, Renatured membrane overlaid with ${ }^{35}$ S]filamin showing specific binding to GST-Kv4.2. Bottom panel, Ponceau S-stained membrane showing the position and similar abundance of proteins in each lane. $D$, Filter overlay assay showing direct in vitro binding of HA-filamin to in vitrotranslated Kv4.2, but not to Kv4.2/600 nor Kv4.2/ATAA. In all, $15 \mu$ l of in vitro-translated $\left[{ }^{35} \mathrm{~S}\right] \mathrm{Kv} 4.2,\left[{ }^{35} \mathrm{~S}\right] \mathrm{Kv} 4.2 / 600$, and $\left[{ }^{35} \mathrm{~S}\right] \mathrm{Kv} 4.2 / \mathrm{ATAA}$ was resolved by SDS-PAGE and transferred to a PVDF membrane. Top panel, Renatured membrane overlaid with in vitro-translated HA-filamin and immunoblotted with anti-HA showing specific binding to Kv4.2, but not to Kv4.2/600 nor Kv4.2/ATAA. Bottom panel, The identical blot was stripped and exposed to autoradiography, showing the position and similar abundance of the in vitro-translated protein products in each lane.
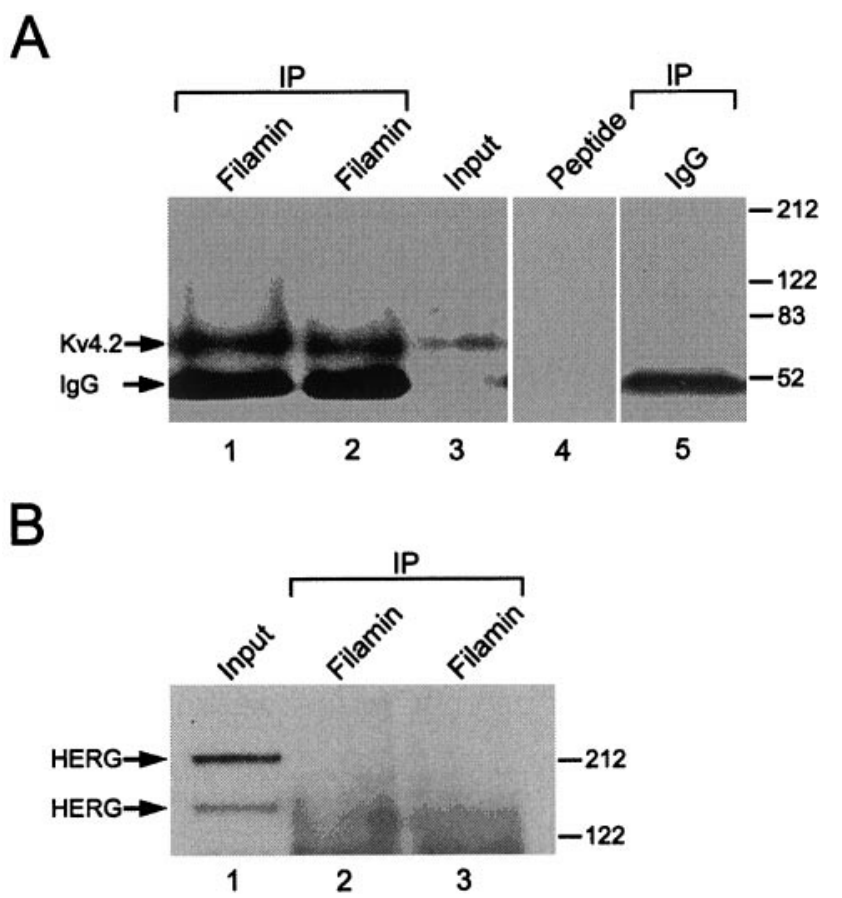

Figure 3. Biochemical association of Kv4.2 and filamin in rat brain. Shown is the coimmunoprecipitation of Kv4.2 and filamin from cerebellum. Membrane fractions of cerebellar homogenate were solubilized and immunoprecipitated as indicated. $A$, The immunoblot shows that two different antifilamin antibodies (lane 1, Sigma; lane 2, Serotec) specifically precipitate $\mathrm{Kv} 4.2$, as visualized by blotting with an anti-Kv4.2 antibody. Immunoprecipitation with control IgG (lane 5) does not pull down Kv4.2, demonstrating the specificity of the immunoprecipitation and competition of the anti-Kv4.2 antibody; the immunogenic peptide completely blocked the labeling of Kv4.2 (lane 4). The Input lane was loaded with $5 \%$ of the extract used for immunoprecipitation (lane 3). B, The immunoblot shows that two different anti-filamin antibodies (lane 2, Sigma; lane 3, Serotec) do not pull down HERG, as visualized by blotting with an anti-HERG antibody. The Input lane was loaded with $5 \%$ of the extract that was used for immunoprecipitation (lane 1).

immunoprecipitates were resolved by SDS-PAGE and immunoblotted with anti-HA and anti-myc antibodies. As shown in Figure $2 A$, HA-filamin was able to coimmunoprecipitate myc-Kv4.2 (lane 4 ). In contrast, HA-filamin was not able to coimmunoprecipitate myc-Kv4.2/600 (lane 5), a deletion construct in which the last 30 aa, including the PTPP binding site, had been removed, nor mycKv4.2/ATAA (lane 6), a construct in which the PTPP binding motif had been substituted with ATAA, indicating the specificity of the Kv4.2/filamin association. In cells singly transfected with HAfilamin or myc-Kv4.2, no myc-Kv4.2 was detected in the immunoprecipitates isolated with the anti-HA antibody (Fig. $2 A$, lanes 2 and 3 , respectively). To demonstrate the specificity of this interaction further, we cotransfected the cells with HA-filamin and mycHERG. Figure $2 A$ shows that HA-filamin was unable to coimmunoprecipitate myc-HERG (lane 7) although myc-HERG was detected readily in cell lysates (lane 8). Reciprocal immunoprecipitations were performed with Kv4.2-transfected filamin ${ }^{+}$and filamin $^{-}$cells. Figure $2 B$ shows that Kv4.2 was able to coimmunoprecipitate filamin from filamin ${ }^{+}$cells, but not from filamin ${ }^{-}$cells.

Direct interaction of Kv4.2 and filamin was tested in a filter overlay assay that used a GST-Kv4.2 bacterial fusion protein and in vitro-translated $\left[{ }^{35}\right.$ S]filamin (Fig. $2 C$ ). A purified GST-Kv4.2 (aa 471-630) fusion protein and GST alone were separated by SDSPAGE and transferred to a PVDF membrane. The proteins were renatured on the membrane and probed with in vitro-translated $\left[{ }^{35}\right.$ S]filamin. Filamin bound to the GST-Kv4.2 fusion protein but did not bind GST alone (Fig. 2C, top panel). Moreover, when the overlay assay was performed on non-renatured membranes, the interaction was abolished, indicating that Kv4.2 must be in a native 
Figure 4. Colocalization of Kv4.2 and filamin in cultured hippocampal neurons. Cultured hippocampal neurons were double-immunolabeled by using anti-Kv4.2 $(A, C, E)$, anti-synaptophysin $(B$, $D)$, and anti-filamin $(F)$ antibodies. $A-D$, Double immunolabeling of endogenous Kv4.2 and synaptophysin shows that Kv4.2 is distributed in a punctate pattern along dendrites, matching closely with that of synaptophysin. $E, F$, Double immunolabeling of endogenous Kv4.2 and filamin shows that Kv4.2 and filamin colocalize in a punctate pattern along the dendrites. Large insets in $E$ and $F$ represent high magnification view of small insets in each panel, respectively.
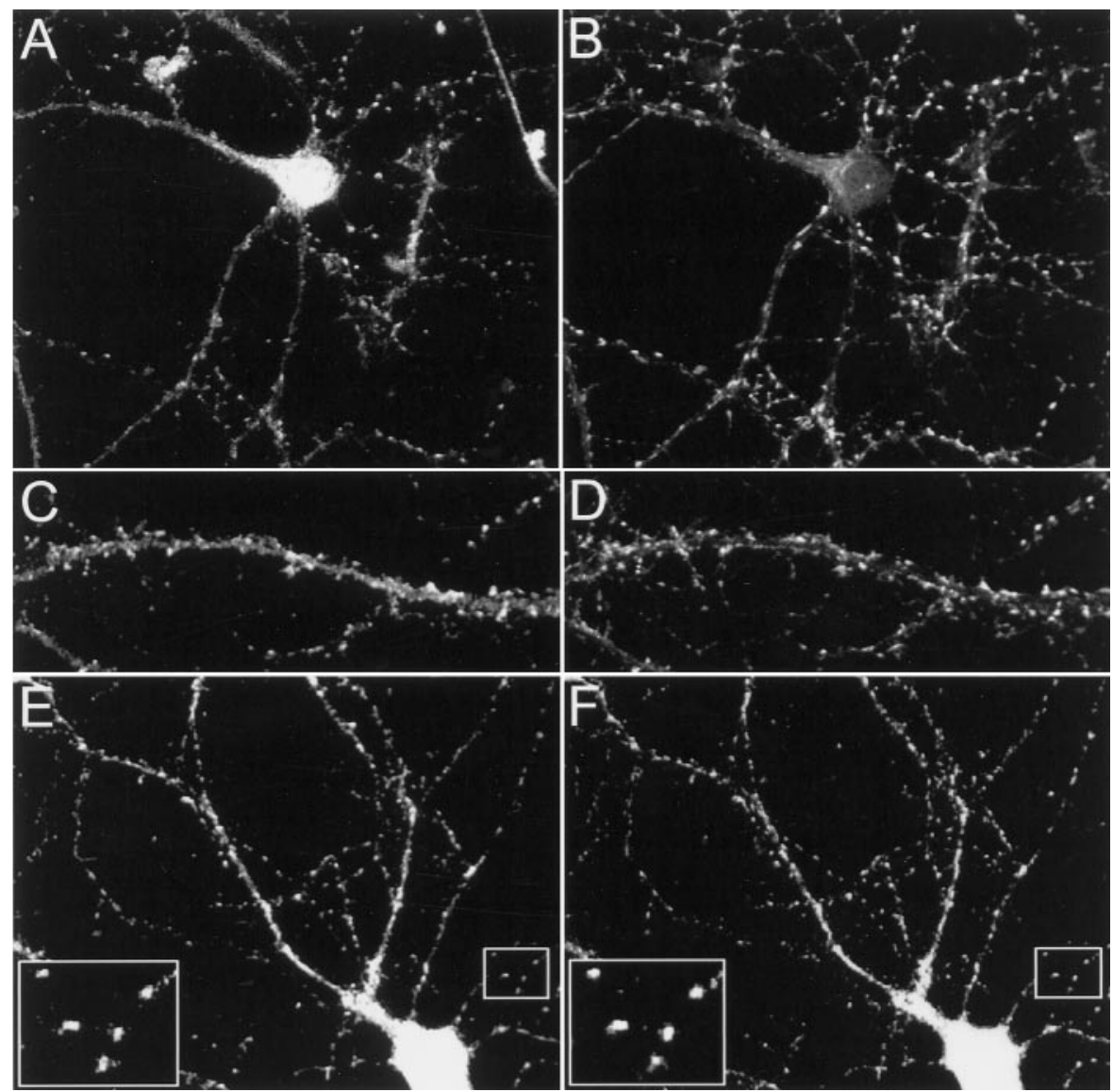

conformation for association with filamin. To demonstrate the specificity of this interaction further, we separated in vitrotranslated $\left[{ }^{35} \mathrm{~S}\right] \mathrm{Kv} 4.2,\left[{ }^{35} \mathrm{~S}\right] \mathrm{Kv} 4.2 / 600$, and $\left[{ }^{35} \mathrm{~S}\right] \mathrm{Kv} 4.2 / \mathrm{ATAA}$ by SDS-PAGE and transferred them to a PVDF membrane. The proteins were renatured on the membrane and probed with in vitro-translated HA-filamin. Figure $2 D$ (top panel) shows that, on immunoblotting with an anti-HA antibody, filamin specifically interacts with Kv4.2 (lane 1, top panel), but not Kv4.2/600 (lane 2, top panel) nor Kv4.2/ATAA (lane 3, top panel). Taken together, these data show that Kv4.2 and filamin form a complex in heterologous cells and that they interact directly in an in vitro assay.

\section{Association of Kv4.2 and filamin in vivo}

To determine whether Kv4.2 and filamin interact in vivo, we performed coimmunoprecipitation experiments from rat cerebellum. Membrane fractions from rat cerebellar homogenates were solubilized, and the supernatant was immunoprecipitated with two distinct anti-filamin antibodies. The immunoprecipitates were resolved by SDS-PAGE, transferred to a PVDF membrane, and immunoblotted with an anti-Kv4.2 antibody (Fig. $3 A$ ). A band at $\sim 74 \mathrm{kDa}$ is seen with anti-Kv4.2 immunoblotting, indicating that filamin is able to coimmunoprecipitate Kv4.2 (Fig. 3A, lanes 1, 2). $\mathrm{Kv} 4.2$ was not precipitated when control $\mathrm{IgG}$ was used as the precipitating antibody (lane 5), indicating the specificity of the coimmunoprecipitation. Moreover, competition of the anti-Kv4.2 antibody with the immunogenic peptide completely blocked the labeling of Kv4.2 band (lane 4). As a further control demonstrating the specificity of this interaction, we determined whether filamin was also capable of immunoprecipitating HERG. Figure $3 B$ shows that, although HERG was readily detectable in brain lysates (Fig. $3 B$, lane 1 ), no HERG could be immunoprecipitated with either anti-filamin antibody (Fig. 3B, lanes 2, 3). These data demonstrate that Kv4.2 and filamin form a complex in brain.

\section{Kv4.2 colocalizes with filamin in cultured hippocampal neurons}

The results described above show that Kv4.2 and filamin interact both in vitro and in brain. Do filamin and Kv4.2 colocalize in neurons? This question was addressed by determining the localization of endogenous Kv4.2 and filamin in cultured hippocampal neurons. As shown in Figure 4, $A-D$, Kv4.2 exhibits a punctate staining pattern along dendrites, matching closely that of the presynaptic marker synaptophysin. Colabeling of endogenous Kv4.2 and endogenous filamin shows that filamin colocalizes with Kv4.2 in dendrites with an enrichment at synapses (Fig. 4E,F). Thus, at the light microscope level, filamin colocalizes with $\mathrm{Kv} 4.2$ in dendrites.

\section{Kv4.2 and filamin colocalize in cerebellum}

Kv4.2 immunoreactivity is present at high levels in the granule cell layer of the cerebellar cortex, exhibiting a somatodendritic localization (Sheng et al., 1992). As such, we used high-resolution confocal imaging to determine whether Kv4.2 and filamin colocalize in cerebellar sections, using a previously characterized antiKv4.2 antibody (Barry et al., 1995). Figure $5 A$ shows that Kv4.2 is expressed abundantly in the cerebellar granule cell layer, consistent with Sheng et al. (1992), and that there is an overlap between Kv4.2 and filamin immunoreactivity in this cell layer. To determine whether this colocalization represents a synaptic localization, we determined whether Kv4.2 immunoreactivity correlated with that of the synaptic marker synaptophysin. Figure $5 B$ shows that the Kv4.2 expression pattern highly correlates with that of synaptophysin. Thus, at the light microscope level, these data show that Kv4.2 and filamin share an overlapping expression pattern in the granule cell layer of the cerebellum, consistent with the direct association of these proteins in vivo. 

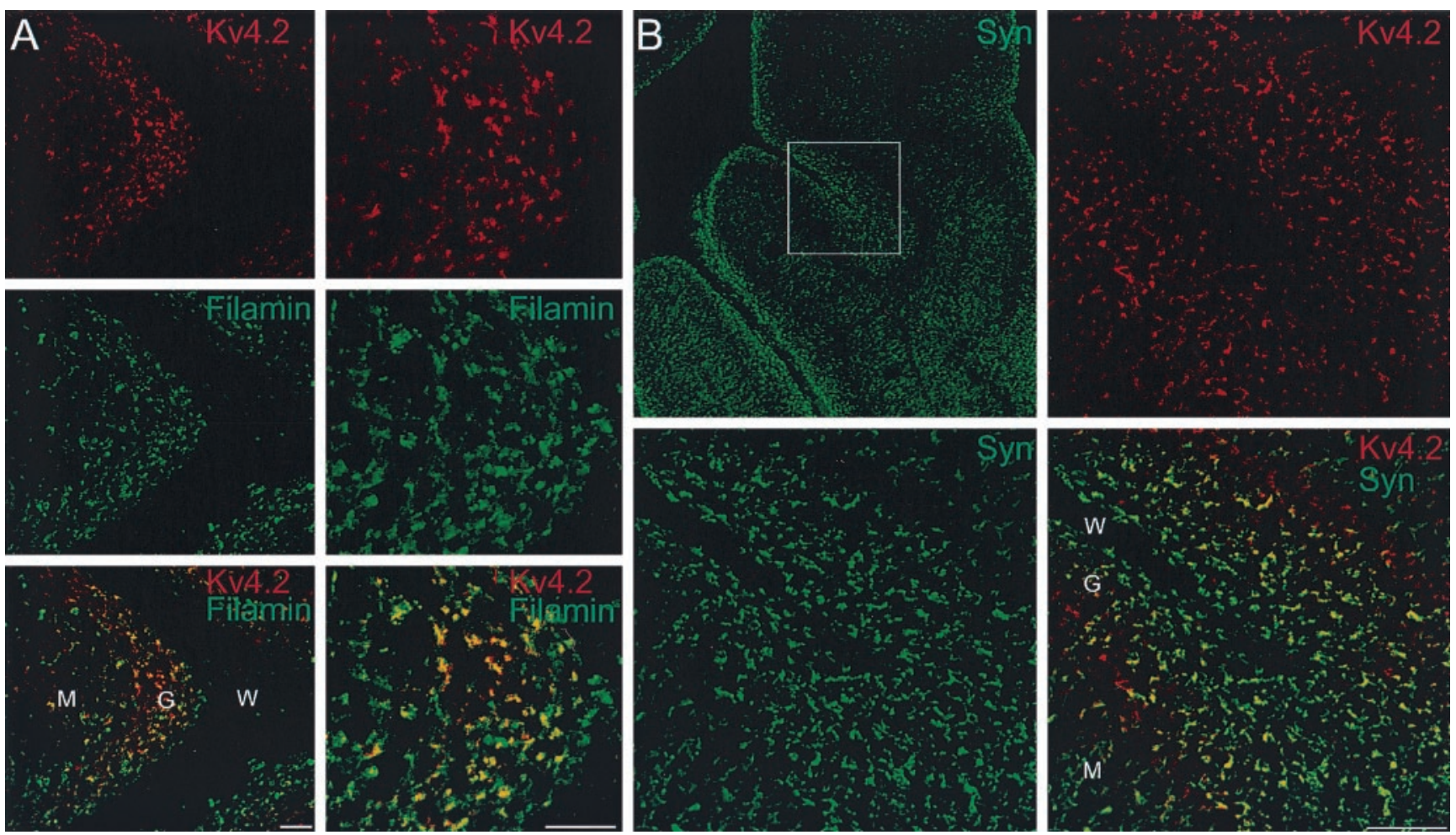

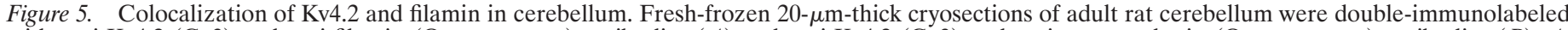

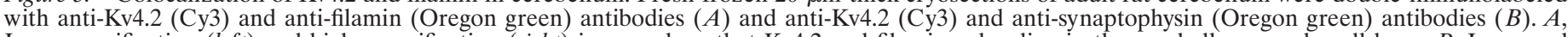

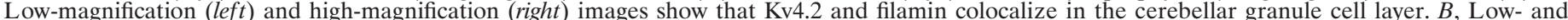

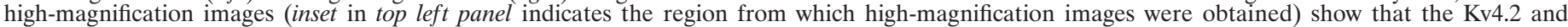
synaptophysin distribution patterns overlap. $G$, Granule cell layer; $M$, molecular layer; $W$, white matter. Scale bars: $A, 50 \mu$ m; $B, 100 \mu$ m.

\section{Filamin localizes Kv4.2 to filopodial roots in heterologous cells}

To examine whether filamin colocalizes with Kv4.2 in heterologous cells and to determine the significance of this interaction on Kv4.2 localization, we transfected myc-Kv4.2 into a filamin-deficient human malignant melanoma cell line (M2) and a M2 cell line stably expressing filamin (Cunningham et al., 1992) and analyzed their localization immunocytochemically. Figure $6, A$ and $B$, shows that myc-Kv4.2 accumulates and colocalizes with filamin in filamin ${ }^{+}$ M2 cells at the roots of filopods. Filamin localization at the roots of filopods is consistent with a previous report demonstrating the role of filamin in the induction of filopodia (Ohta et al., 1999). In contrast, Kv4.2 expression in filamin ${ }^{-}$M2 cells shows a more uniform expression pattern, with no localization at filopodial roots (Fig. 6G,H). To determine whether the loss of Kv4.2 localization at filopodial roots is directly attributable to the absence of the filamin interaction or to a general loss of filamin expression, we transfected nonfilamin-interacting myc-Kv4.2/600 and myc-Kv4.2/ATAA mutant channels into filamin ${ }^{+}$M2 cells. Similar to wild-type Kv4.2 distribution in filamin ${ }^{-} \mathrm{M} 2$ cells, neither myc-Kv4.2/600 nor mycKv4.2/ATAA colocalizes with filamin in filamin ${ }^{+} \mathrm{M} 2$ cells, but each shows a more uniform expression pattern with no specific localization (Fig. $6 C-F$ ). These data demonstrate that Kv4.2 colocalizes with filamin in heterologous cells and that the accumulation of Kv4.2 at filamin-rich filopodial roots is dependent on its interaction with filamin.

\section{Effect of Kv4.2-filamin association on whole-cell Kv4.2 current density}

To determine the significance of the Kv4.2-filamin association on whole-cell Kv4.2 current, we recorded, using the patch-clamp technique, the current generated from Kv4.2-transfected filamin ${ }^{+}$and filamin $^{-}$cells in whole-cell clamp mode. As is evident from the recordings, there is a prominent transient outward current present in Kv4.2-transfected cells in the presence or absence of filamin.
However, the current density, measured from the initial transient outward peak to the current level at the end of the $500 \mathrm{msec}$ step, was 2.6-fold greater in the filamin ${ }^{+}$cells than in the filamin ${ }^{-}$cells (Fig. $7 A, B$ ). This also is reflected in the bar graph (Fig. $7 F$ ). These results demonstrate that $\mathrm{Kv} 4.2$ channels are expressed functionally and suggest that their interaction with filamin enhances the current density. To determine whether this difference in whole-cell current density was directly attributable to the Kv4.2-filamin interaction or to a nonspecific lack of filamin in filamin ${ }^{-}$cells, we expressed the Kv4.2/ATAA nonfilamin-interacting mutant channel in filamin ${ }^{+}$ cells. As shown in Figure $7 C$, the magnitude of the whole-cell Kv4.2/ATAA current density was 2.8-fold less than that of wildtype Kv4.2 expressed in filamin ${ }^{+}$cells and similar to that of wild-type Kv4.2 expressed in filamin ${ }^{-}$cells. This is reflected in the bar graph (Fig. $7 F$ ). It is noteworthy that the Kv4.2/ATAA currents had markedly slower inactivation kinetics as compared with wildtype Kv4.2, most likely resulting from a nonfilamin-related effect on $\mathrm{C}$-type channel inactivation. Experiments conducted with untransfected or mock-transfected cells never expressed a transient outward current. Instead, a small, relatively rapidly activating endogenous delayed rectifier current generally was observed that did not inactivate during the $500 \mathrm{msec}$ step (see Fig. 6D,E). The same endogenous current also could be revealed in cells expressing Kv4.2 current when the Kv4.2 channels were inactivated by changing the holding potential from -80 to $-20 \mathrm{mV}$. Last, Kv4.2 currents were blocked reversibly by $10 \mathrm{~mm}$ 4-aminopyridine $(n=8$; data not shown).

To determine whether the $\sim 2.7$-fold increase in whole-cell Kv4.2 current density is attributable to a higher density of channels in the surface membrane or to a change in the single-channel conductance, we assessed the single-channel conductance of Kv4.2 expressed in each of these cell lines. In agreement with previous studies (Cooper and Shrier, 1985; Cooper and Shrier, 1989), we found single-channel conductances with high $\mathrm{K}^{+}$concentration in the pipette medium to be $46.0 \pm 1.79 \mathrm{pS}(n=5)$ and $43.6 \pm 1.33$ 

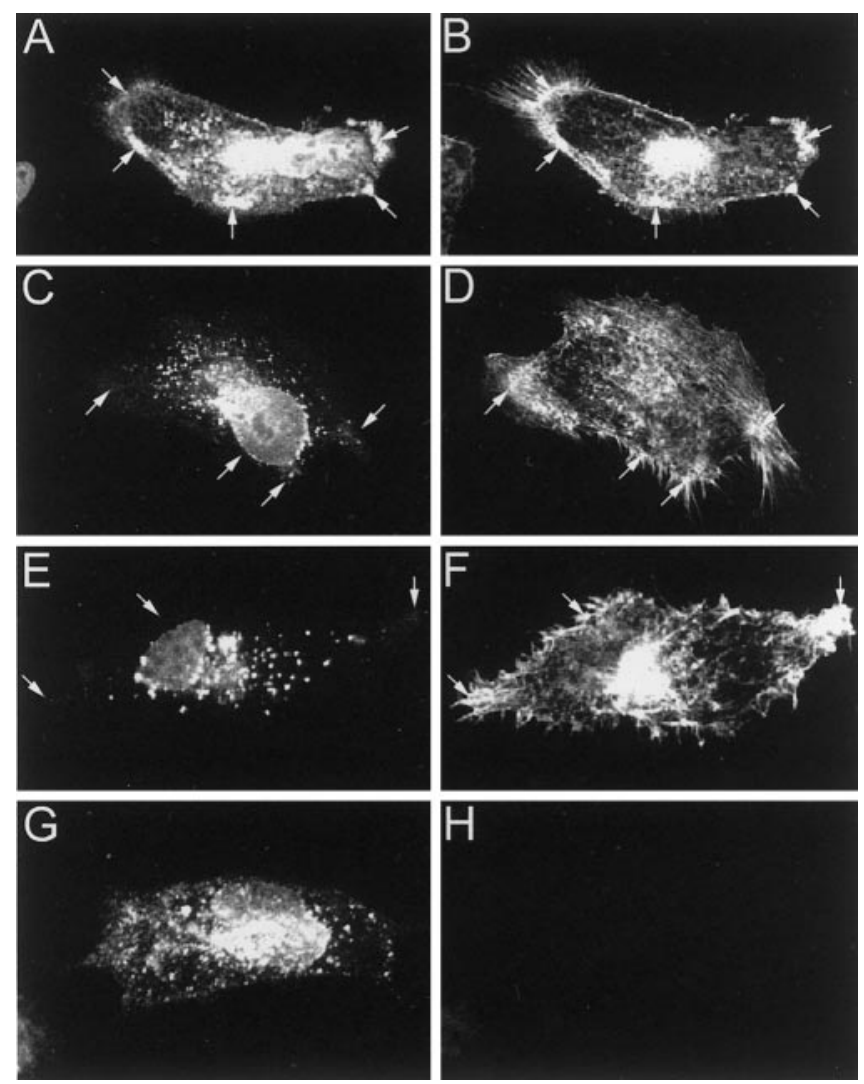

Figure 6. Colocalization and accumulation of Kv4.2 and filamin at filopodial roots in filamin ${ }^{+}$heterologous cells. Filamin ${ }^{+} \mathrm{M} 2$ cells were transfected with myc-Kv4.2 $(A, B)$, myc-Kv4.2/600 $(C, D)$, and myc-Kv4.2/ATAA $(E, F)$. Filamin ${ }^{-}$M2 cells were transfected with myc-Kv4.2 $(G, H)$. Cells were double-immunolabeled with anti-myc $(A, C, E, G)$ and anti-filamin $(B$, $D, F, H)$ antibodies. $A, B, \mathrm{Kv} 4.2$ exhibits a discrete subcellular distribution, colocalizing with filamin at filopodial roots in filamin ${ }^{+} \mathrm{M} 2$ cells. $C, D$, Deletion of the C-terminal 30 aa of Kv4.2, including the filamin-binding site (Kv4.2/600), and substitution of the prolines with alanines within the filamin-binding site of Kv4.2 (Kv4.2/ATAA; $E, F)$ results in a loss of Kv4.2 colocalization with filamin and a resulting nonspecific distribution with a marked absence at filopodial roots in filamin ${ }^{+} \mathrm{M} 2$ cells. $G, H, \mathrm{Kv} 4.2$ exhibits a nonspecific distribution in filamin ${ }^{-}$M2 cells. Arrows indicate $\mathrm{Kv} 4.2$ and filamin localization at filopodial roots.

$\mathrm{pS}(n=5)$ in filamin $^{+}$and filamin ${ }^{-}$cells, respectively (data not shown). This difference was determined not to be statistically significant. As a further control we transfected the HERG $\mathrm{K}^{+}$ channel into filamin ${ }^{+}(n=4)$ and filamin ${ }^{-}(n=4)$ cells and recorded the magnitude of the whole-cell current. Our results revealed no difference in current density between these cell lines (data not shown). Moreover, total cellular Kv4.2 protein expression is equivalent in filamin ${ }^{+}$and filamin ${ }^{-}$cells (see Fig. $2 B$, bottom panel). Taken together, the electrophysiological data reveal that Kv4.2 is expressed in the surface membrane in the presence or absence of the filamin interaction; however, the presence of the interaction results in an increase in the density of Kv4.2 channels that are expressed in the surface membrane.

\section{DISCUSSION}

Here we report a novel protein-protein interaction between Kv4.2 and filamin, a member of the $\alpha$-actinin/spectrin/dystrophin family of actin-binding proteins. We have defined a PTPP motif in the C terminus of Kv4.2 (aa 601-604) that is required for filamin interaction. Deletion or mutation of this motif abolishes the interaction, as determined by the yeast two-hybrid assay. We also show that Kv4.3, which contains the identical C-terminal tail PTPP motif, also interacts with filamin in the yeast two-hybrid assay. In addition, we demonstrate that Kv4.2 and filamin directly interact in in vitro assays and can be coimmunoprecipitated from heterologous cells
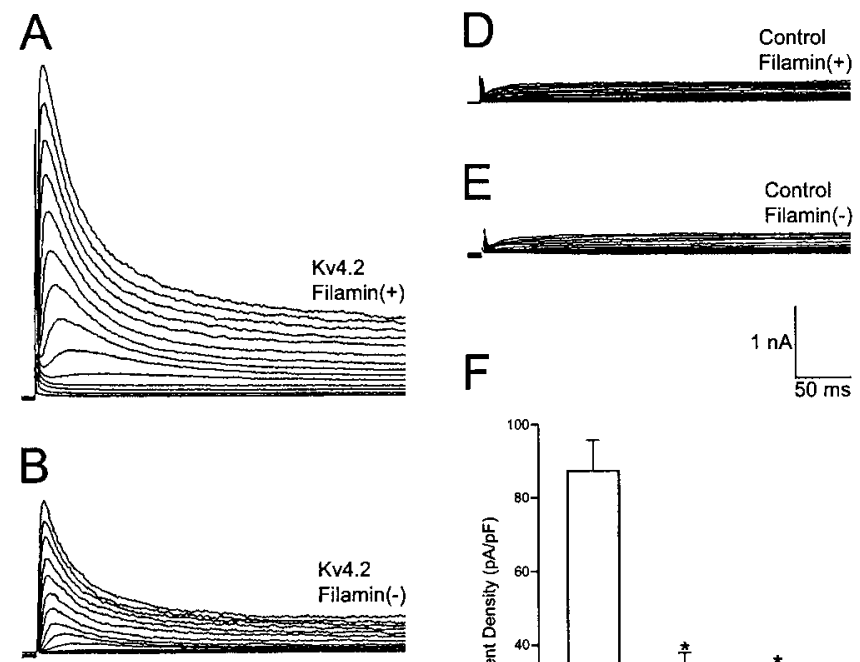

$\mathrm{F}$
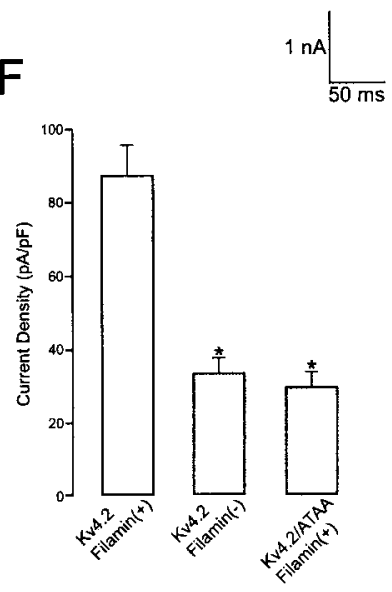

Figure 7. Effect of the Kv4.2-filamin association on whole-cell Kv4.2 current density. Large, transient whole-cell currents were induced in filamin $^{+}$cells transfected with Kv4.2 $(A)$ by 500 msec depolarizing steps from $\mathrm{a}-80 \mathrm{mV}$ holding potential to potentials between -70 and $70 \mathrm{mV}$ in $10 \mathrm{mV}$ steps that were imposed at $10 \mathrm{sec}$ intervals. Recordings from filamin ${ }^{-}$cells transfected with Kv4.2 (B) and filamin ${ }^{+}$cells transfected with Kv4.2/ATAA (C) revealed a smaller transient outward current. In untransfected filamin ${ }^{+}$ $(D)$ or filamin $^{-}(E)$ cells this transient current was not observed. Instead, a delayed rectifier-like endogenous current was recorded. Similar endogenous currents were revealed in filamin ${ }^{+}$and filamin ${ }^{-}$cells transfected with Kv4.2 by imposing the depolarizing step protocol from a $-20 \mathrm{mV}$ holding potential (data not shown). The differences in the magnitude of the transient outward current as measured from the initial transient outward peak to the current level at the end of the $500 \mathrm{msec}$ depolarizing steps to $+30 \mathrm{mV}$ were found to be 2.6-fold greater in Kv4.2-transfected filamin ${ }^{+}$cells $(n=$ $22)$ than in filamin ${ }^{-}$cells $\left(n=15 ;{ }^{*} p<0.001\right)$ and 2.8 -fold greater in Kv4.2-transfected filamin ${ }^{+}$cells than in Kv4.2/ATAA-transfected filamin ${ }^{+}$ cells $\left(n=15 ;{ }^{*} p<0.001\right)$. This difference is reflected in the bar graph $(F)$.

and rat brain extracts. Furthermore, immunolabeling experiments reveal that Kv4.2 and filamin share an overlapping expression pattern in the cerebellum and cultured hippocampal neurons.

Immunocytochemical analyses show that Kv4.2 is enriched and colocalizes with filamin at cellular specializations: the roots of filopods in filamin ${ }^{+}$heterologous cells. Deletion or mutation of the Kv4.2-binding motif abolishes this enrichment and colocalization, indicating that filamin plays a role in Kv4.2 localization. Expression of Kv4.2 in filamin ${ }^{-}$cells also results in a loss of Kv4.2 localization at filopodial roots. Moreover, the magnitude of whole-cell Kv4.2 current density is $\sim 2$.7-fold larger in filamin ${ }^{+}$cells as compared with these currents in filamin ${ }^{-}$cells. The combined immunocytochemical and electrophysiological data indicate that the observed difference in the magnitude of whole-cell Kv4.2 current density most likely is attributable to an increase in the number of functional channels in the surface membrane as opposed to a change in the single-channel conductance of Kv4.2. Taken together, these findings indicate that filamin is a Kv4.2-interacting cytoskeletal protein that colocalizes with Kv4.2 in neurons and plays an important role in the localization and functional surface membrane of Kv4.2 in heterologous cells.

\section{What determines filamin localization?}

The data presented in this study and others indicate that filamin exhibits a restricted distribution within the cell, localized primarily at cellular specializations, e.g., focal adhesion sites (Burridge and Chrzanowska-Wodnicka, 1996; Schwarzman et al., 1999) and filopodial roots (Ohta et al., 1999). This restricted localization may 
be attributable to its interaction with the adhesion molecule integrin, a constituent protein of cellular specializations (Burridge and Chrzanowska-Wodnicka, 1996). Interestingly, both integrin and filamin have been implicated as molecular components of the neuromuscular junction (NMJ), and $\beta 1$-integrin has been shown to play a physiological role in the agrin-mediated signaling cascade that leads to AChR clustering (Meier and Wallace, 1998). Similarly, filamin has been implicated in stabilizing AChR clustering at the NMJ (Shadiack and Nitkin, 1991) and recently has been shown to interact directly with sarcoglycan (Thompson et al., 2000).

\section{Role of filamin at the synapse?}

This study demonstrates that filamin colocalizes and interacts with Kv4.2 in neurons. Using the yeast two-hybrid assay, we mapped the filamin interaction site on Kv4.2 to a proline-rich region (PTPP) at aa 601-604. This PTPP motif constitutes a consensus SH3-binding module (Pawson and Scott, 1997); however, no SH3 domains were found within filamin. Alternatively, the dependence of binding on prolines suggests a role for these amino acids in establishing the appropriate secondary structure that is required for Kv4.2-filamin interaction. A similar proposal has been made for the interaction between group 1 metabotropic glutamate receptors and Homer proteins (Tu et al., 1998).

The postsynaptic localization of Kv4.2 is consistent with the involvement of this fast-transient $\mathrm{K}^{+}$channel in regulating the excitability of the postsynaptic membrane and thus the reception and integration of synaptic signals (Sheng et al., 1992; Alonso and Widmer, 1997). The combined immunocytochemical and electrophysiological findings presented here support two overlapping roles for filamin with respect to Kv4.2 binding: surface membrane expression and subcellular localization of Kv4.2.

In heterologous cells, filamin is necessary for the induction of filopodia (Ohta et al., 1999). A model has been put forth in which dendritic spine formation results from the induction of filopodiallike dendritic spine precursors under synaptic boutons on axons (Matus, 1999). Filamin also has been demonstrated to exist in two intracellular pools in a phosphorylation-dependent manner: one associated with the plasma membrane and the other within the actin cytoskeletal network (Sharma et al., 1995; Meyer et al., 1997; Ott et al., 1998). Thus, signaling events at the PSD may regulate the extent of Kv4.2 expression in the surface membrane via its interaction with filamin.

What is the importance of positioning this $\mathrm{K}^{+}$channel in such a restricted manner? The answer may lie not within the ion channel but in the complex with which it is associated. Modulatory enzymes precisely localized to the subsynaptic membrane could provide a rapid activity-dependent mechanism for the regulation of channel expression in the surface membrane and/or channel kinetics, thus modulating postsynaptic excitability. In fact, a role for PKC in Kv4.2 and filamin modulation has been established (Nakamura et al., 1997; Glogauer et al., 1998). Interestingly, PKC has been shown to bind $\beta$-integrin ( $\mathrm{Ng}$ et al., 1999), while the interaction of $\beta$-integrin with filamin has been clearly established (Sharma et al., 1995; Loo et al., 1998; Pfaff et al., 1998). Thus, via its interaction with Kv4.2 and $\beta$-integrin, filamin may serve as a molecular scaffold to localize Kv4.2 to the postsynaptic membrane and/or to mediate the assembly of a macromolecular complex linking Kv4.2 to the actin cytoskeleton and signaling molecules. A similar signaling complex has been described within which Yotiao, a scaffold protein that directly links the NMDA receptor with type I protein phosphatase and cAMP-dependent protein kinase, facilitates the regulation of channel activity (Westpal et al., 1999).

The ability of filamin to localize Kv4.2 to cellular specializations and stabilize its expression in the surface membrane in heterologous cells identifies it as a candidate protein involved in Kv4.2 localization and surface membrane expression at the synapse. Further characterization of the Kv4.2/filamin interaction in neurons will be required to address the role of filamin in Kv4.2 localization at the neuronal synapse.

\section{REFERENCES}

Alonso G, Widmer H (1997) Clustering of Kv4.2 potassium channels in postsynaptic membrane of rat supraoptic neurons: an ultrastructural study. Neuroscience 77:617-621.

Arnold DB, Clapham DE (1999) Molecular determinants for subcellular localization of PSD-95 with an interacting $\mathrm{K}^{+}$channel. Neuron 23:149-157.

Barry DM, Trimmer JS, Merlie JP, Nerbonne JM (1995) Differential expression of voltage-gated $\mathrm{K}^{+}$channel subunits in adult rat heart. Circ Res 77:361-369.

Burridge K, Chrzanowska-Wodnicka M (1996) Focal adhesions, contractility, and signaling. Annu Rev Cell Dev Biol 12:463-518.

Colledge M, Froehner SC (1998) To muster and cluster: anchoring neurotransmitter receptors and synapses. Proc Natl Acad Sci USA 95:3341-3343.

Cooper E, Shrier A (1985) Single-channel analysis of fast transient potassium currents from nodose neurons. J Physiol (Lond) 369:199-208.

Cooper E, Shrier A (1989) Inactivation of A currents and A channels on rat nodose neurons in culture. J Gen Physiol 94:991-910.

Craven SE, Bredt DS (1998) PDZ proteins organize synaptic signaling pathways. Cell 93:495-498.

Cunningham CC, Gorlin JB, Kwiatowski DJ, Hartwig JH, Janmey PA, Byers R, Stossel TP (1992) Actin-binding protein requirement for cortical stability and efficient locomotion. Science 255:325-326.

Glogauer M, Arora P, Chou D, Janmey PA, Downey GP, McCulloch CAG (1998) The role of actin-binding protein 280 in integrin-dependent mechanoprotection. J Biol Chem 273:1689-1698.

Hartwig J, Stossel T (1975) Isolation and properties of actin, myosin, and a new action-binding protein in rabbit alveolar macrophages. J Biol Chem 250:5696-5705.

Hille B (1991) Ionic channels of excitable membranes, 2nd Ed. Sunderland, MA: Sinauer.

Jan LY, Jan YN (1997) Cloned potassium channels from eukaryotes and prokaryotes. Annu Rev Neurosci 20:91-123.

Loo DT, Kanner SB, Aruffo A (1998) Filamin binds to the cytoplasmic domain of $\beta 1$-integrin. J Biol Chem 273:23304-23312.

Luo J, Wang Y, Yasuda RP, Dunah AW, Wolfe BB (1997) The majority of $N$-methyl-D-aspartate receptor complexes in adult rat cerebral cortex contain at least three different subunits (NR1/NR2A/NR2B). Mol Pharmacol 51:79-86.

Magee J, Hoffman D, Colbert C, Johnston D (1998) Electrical and calcium signaling in dendrites of hippocampal pyramidal neurons. Annu Rev Physiol 60:327-346.

Maletic-Savatic M, Lenn NJ, Trimmer JS (1995) Differential spatiotemporal expression of $\mathrm{K}^{+}$channel polypeptides in rat hippocampal neurons developing in situ and in vitro. J Neurosci 15:3840-3851.

Marti A, Luo Z, Cunningham C, Ohta Y, Hartwig J, Stossel TP, Kyriakis JM, Avruch J (1997) Actin-binding protein-280 binds the stressactivated protein kinase (SAPK) activator SEK-1 and is required for tumor necrosis factor- $\alpha$ activation of SAPK in melanoma cells. J Biol Chem 272:2620-2628.

Matus A (1999) Postsynaptic actin and neuronal plasticity. Curr Opin Neurobiol 9:561-565

Meier T, Wallace BG (1998) Formation of the neuromuscular junction: molecules and mechanisms. BioEssays 20:819-829.

Meyer SC, Zuerbig S, Cunningham CC, Hartwig JH, Bissell T, Gardner K, Fox JE (1997) Identification of the region in actin-binding protein that binds to the cytoplasmic domain of glycoprotein IB $\alpha$. J Biol Chem 272:2914-2919.

Nakamura TY, Coetzee WA, Vega-Saenz De Miera E, Artman M, Rudy B (1997) Modulation of Kv4 channels, key components of rat ventricular transient outward $\mathrm{K}^{+}$current, by PKC. Am J Physiol 273:H1775-H1786.

Ng T, Shima D, Squire A, Bastiaens PIH, Gschmeissner S, Humphries MJ, Parker PJ (1999) PKC $\alpha$ regulates $\beta 1$ integrin-dependent cell motility through association and control of integrin traffic. EMBO J 18:3909-3923.

Ohta Y, Suzuki N, Nakamura S, Hartwig J, Stossel TP (1999) The small GTPase RalA targets filamin to induce filopodia. Proc Natl Acad Sci USA 96:2122-2128.

Ott I, Fischer EG, Miyagi Y, Mueller BM, Ruf W (1998) A role for tissue factor in cell adhesion and migration mediated by interaction with actinbinding protein 280. J Cell Biol 140:1241-1253.

Pawson T, Scott JD (1997) Signaling through scaffold, anchoring, and adaptor proteins. Science 278:2075-2080.

Petrecca K, Atanasiu R, Grinstein S, Orlowski J, Shrier A (1999) Subcellular localization of the $\mathrm{Na}^{+} / \mathrm{H}^{+}$exchanger $\mathrm{NHE} 1$ in rat myocardium. Am J Physiol 276:H709-H717.

Pfaff M, Shouchun L, Erle DJ, Ginsberg MH (1998) Integrin- $\beta$ cytoplasmic domains differentially bind to cytoskeletal proteins. J Biol Chem 273:6104-6109.

Pond AL, Scheve BK, Benedict AT, Petrecca K, Van Wagoner DR, Shrier A, Nerbonne JM (2000) Expression of distinct ERG protein in rat, mouse, and human heart: relation to functional $\mathrm{I}_{\mathrm{Kr}}$ channels. J Biol Chem 275:5997-6006.

Schwarzman AL, Singh N, Tsiper M, Gregori L, Dranovsky A, Vitek MP, Glabe C, St. George-Hyslop PH, Goldgaber D (1999) Endogenous pre- 
senilin 1 redistributes to the surface of lamellipodia upon adhesion of Jurkat cells to a collagen matrix. Proc Natl Acad Sci USA 96:7932-7937.

Shadiack AM, Nitkin RM (1991) Agrin induces $\alpha$-actinin, filamin, and vinculin to colocalize with AChR clusters on cultured chick myotubes. J Neurobiol 22:617-628.

Sharma CP, Ezzell RM, Arnaout MA (1995) Direct interaction of filamin (ABP-280) with the $\beta 2$-integrin subunit CD18. J Immunol 154:3461-3470.

Sheng M (1996) PDZs and receptor/channel clustering: rounding up the latest aspect. Neuron 17:575-578.

Sheng M, Tsaur M-L, Jan YN, Jan LY (1992) Subcellular segregation of two A-type $\mathrm{K}^{+}$channel proteins in rat central neurons. Neuron 9:271-284.

Thompson TG, Chan Y-M, Hack AA, Brosius M, Rajala M, Lidov HGW, McNally EM, Watkins S, Kunkel LM (2000) Filamin 2 (FLN2): a muscle-specific sarcoglycan interacting protein. J Cell Bio 148:115-57826

Tu JC, Xiao B, Yuan JP, Lanahan AA, Leoffert K, Li M, Linden DJ, Worley PF (1998) Homer binds a novel proline-rich motif and links group 1 metabotropic glutamate receptors with $\mathrm{IP}_{3}$ receptors. Neuron 21:717-57826.
Veh RW, Lichtinghagen R, Sewing S, Wunder F, Grumbach IM, Pongs O (1995) Immunohistochemical localization of five members of the Kv1 channel subunits: contrasting subcellular locations and neuron-specific colocalizations in rat brain. Eur J Neurosci 7:2189-578205.

Wang H, Kunkel DD, Schwartzkroin PA, Tempel BL (1994) Localization of Kv1.1 and Kv1.2, two $\mathrm{K}$ channel proteins, to synaptic terminals, somata, and dendrites in the mouse brain. J Neurosci 14:4588-578599.

Westpal RS, Tavalin SJ, Lin JW, Alto NM, Fraser IDC, Langeberg LK, Sheng M, Scott JD (1999) Regulation of NMDA receptors by an associated phosphatase-kinase signaling complex. Science 285:93-5786.

Wyszynski M, Sheng M (1999) Analysis of ion channel-associated proteins. Methods Enzymol 294:371-57885.

Xie Z, Xu W, Davie EW, Chung DW (1998) Molecular cloning of human ABPL, an actin-binding protein homologue. Biochem Biophys Res Commun 251:914-57819.

Ziff EB (1997) Enlightening the postsynaptic density. Neuron 19:1163-578174.

Zito K, Fetter RD, Goodman CS, Isacoff EY (1997) Synaptic clustering of fasciclin II and Shaker: essential targeting sequences and role of Dlg. Neuron 19:1007-578016. 